\title{
Gap analysis of acoustic tracking data reveals spatial and temporal segregation in sympatric reef sharks
}

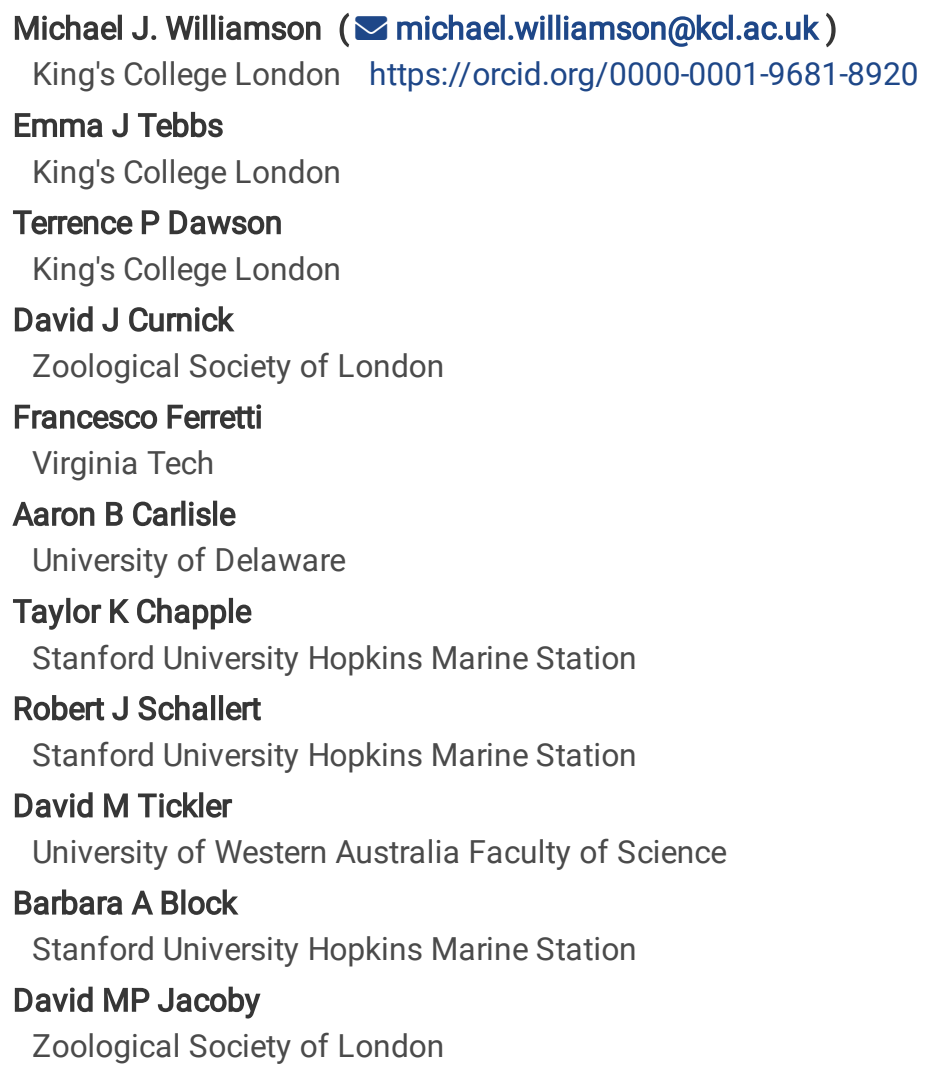

Research

Keywords: acoustic telemetry, animal movement, ecology, elasmobranchs, marine protected areas, network analysis, segregation, spatial, sharks, temporal

Posted Date: January 2nd, 2020

DOI: https://doi.org/10.21203/rs.2.19727/v1

License: (c) (7) This work is licensed under a Creative Commons Attribution 4.0 International License. Read Full License 


\section{Abstract}

Background There are now a wide array of field and laboratory techniques available for gaining insight into the movement and behaviour of sharks. Although acoustic telemetry may lack the fine-scale resolution of satellite telemetry, the low cost and longer battery life make it a powerful tool for investigating elasmobranch behaviour. Here, in the absence of satellite tracking data, we develop a novel approach to analysing acoustic telemetry data, using detection gaps to infer movement patterns to and from monitored reef habitats, to investigate spatial and temporal segregation between two sympatric shark species in a large remote MPA.

Methods A total of 102 grey reef and 76 silvertip sharks were fitted with long-term acoustic transmitters and tracked inside a large acoustic array of reef-based receivers in the British Indian Ocean Territory MPA, between 2014 and 2018. From the resulting dataset (768,081 movements), movements between receivers and recursive loops to the same receiver were identified. Using the durations of inter-receiver movements (i.e. detection gaps), individual behaviours were classified into 'restricted' or 'wider ranging' movements. Drivers of these movements were identified using network analysis, generalised linear mixed models and multi-model inference starting from an a priori set of explanatory variables.

Results In general, silvertip sharks were more likely to undertake 'wider ranging' movements than grey reef sharks. 'Wider ranging' movements were more common at night compared to during the day, and during the wet season compared to the dry season. In addition, the difference in 'wider ranging' movements between the two species increased at night. These results suggest spatial segregation and temporal segregation of movements between grey reef and silvertip sharks in the region.

Conclusions We present a novel analysis of detection gaps from acoustic telemetry data to infer differential movement patterns and describe how species organise in space and time. Furthermore, this approach shows that acoustic telemetry gap analysis can be used for comparative studies, or combined, with other research techniques to better understand the functional role of sharks in reef ecosystems, moving towards more informed strategies for the conservation and management of the marine environment.

\section{Background}

Due to the continued decline of global elasmobranch populations $(1,2)$, investigating the movement ecology, spatial distribution and behaviour of these species is of continued importance for their conservation and management. There are now a wide array of field and laboratory techniques available for gaining insight into the movement and behaviour of sharks (3). Geolocations from satellite telemetry, such as pop-up satellite archival tags (PSATs), can be used to reconstruct estimated tracks of tagged animals that rarely come to the surface, but they are limited by battery life and the low spatial and temporal resolution of estimated positions (4). Acoustic telemetry is regularly used for analysing the long-term movement patterns of coastallyaffiliated elasmobranch species, with a longer battery life enabling data collection over greater time scales, but it too, is limited by both the detection range of the receivers and the low positional accuracy in nonoverlapping arrays (5). Thus, combining methodological approaches, where possible, can minimise these limitations, helping to reveal the mechanisms behind important ecological processes that might aid how elasmobranchs are conserved in the future (6).

The British Indian Ocean territory (BIOT) is a large, remote archipelago declared a 'notake' Marine Protected Area (MPA) in 2010, the reefs of which are home to multiple elasmobranch species $(7,8)$. Reef-associated elasmobranchs inhabit or frequent coral reefs for foraging and mating opportunities, nursery and pupping areas, and protection from larger predators (9-11). Multiple elasmobranch species may coexist in reef ecosystems through differential use of space and time, allowing sympatric species utilise resources and habitat but avoid interspecific competition $(12,13)$. Subordinate species may avoid areas of regular use or high population density of more dominant species, or may alter diel or seasonal rhythms to reduce temporal activity overlap $(13,14)$. As limited resources and high levels of competition can significantly impact an individual's fitness, spatial and temporal segregation can be a critical component of survival (13, 15-17). Investigations into spatio-temporal segregation are, therefore, emerging as an important focus area in elasmobranch ecological research (5-7).

Acoustic telemetry can be a powerful tool for investigating elasmobranch behaviour. It has been used to measure or infer multiple aspects of elasmobranch ecology (18), such as social structuring (19-21) and individual social preferences (22), but is also regularly employed to investigate the spatio-temporal distribution and movement dynamics of elasmobranchs $(5,15,23,24)$. The temporal dynamics of elasmobranch species movement are important for understanding how predators can affect prey both directly, through ingestion, and indirectly, through predation risk (25). This can lead to top down effects through mortality and antipredator behaviour, resulting in changes to prey communities and species abundance (26-29). Temporal changes in the movements of elasmobranchs may also have bottom up effects by impacting nutrient cycle timings in marine ecosystems, such as coral reefs (23). Consequently, the distribution and timing of 
acoustic detection data can be extremely informative at daily, monthly, seasonal, and annual scales. However, there is also an important temporal component within the absences between detections that is often overlooked. Thus, it is important to identify not only the frequency and periodicity of movements to areas of interest (e.g. feeding and breeding areas, resting refugia etc.), but also the time taken for movements between these and other areas (30), specifically, the periods when they are not being detected.

Network analyses of movements derived from acoustic telemetry are becoming more commonplace for exploring spatial and temporal movement patterns within acoustic detection data $(18,21,31)$. To date, gap analysis has been used for studying the ecology of marine vertebrates, particularly using time periods between location fixes from satellite telemetry to determine directed or restricted movements for optimal foraging theory in pinnipeds (32). However, currently, network analyses using acoustic telemetry often ignore the gaps between detections. These gaps can be informative for inferring the length of time (which might be a proxy for tortuosity) taken between movements considered as the edge duration within a movement network (31), and therefore coarse scale behaviour and its associated timings. For example, they can be used to inform the likelihood of elasmobranchs moving out of protected marine areas, into unprotected waters, where they may be vulnerable to exploitation from commercial fisheries (6). These gaps can also be used to estimate the timings of ontogenetic habitat shifts, when individuals begin leaving nursery areas for longer periods (33) and more accurately determining the timings and thresholds to define residency events for spatial distribution and movement analyses (34). As sharks play important direct and indirect roles in marine ecosystems $(35,36)$, detection gaps also have potential to provide information into ecological function in elasmobranchs species, particularly in areas or systems where finescale movement data from satellite telemetry is unavailable. The analysis of detection gaps within acoustic telemetry data can thus directly complement static analyses of presence data, in addition to other telemetric and physiological data, to greatly aid the overall understanding of the role of multi-species predator assemblages within coral reef ecosystems (15).

In this paper we use data gathered across a large array of acoustic receivers monitoring reef-associated shark species throughout the BIOT MPA. In the absence of receivers in pelagic areas and sufficient satellite telemetry data to make population level inferences, we aim to analyse the detection gaps from the acoustic time-series to characterise 'restricted' or 'wider ranging' movement patterns in grey reef and silvertip sharks investigating the spatial and temporal segregation between these two species in coral reef ecosystems.

\section{Methods}

\section{Acoustic tracking}

Data collection was undertaken in the BIOT MPA between February 2013 and April 2019. Throughout the archipelago there have been situated up to 93 permanent and temporary acoustic receivers (VR2W, VR4-UWM, VR4G and VR2AR receivers, Vemco Inc, Nova Scotia, Canada), as configured in Fig. 1. The BIOT MPA is characterised by numerous small islanded atolls with submerged banks and reefs, with waters of $1 \mathrm{~km}$ depth or more separating each atoll or reef system (37). As such, acoustic receivers in the BIOT MPA are mainly based on areas accessible to divers, such as coral reef systems, with few receivers covering the deep pelagic waters of the region. This array was initially started in 2013, expanded throughout subsequent years [for more information see [Carlisle et al. (6)], covering a perimeter of $700 \mathrm{~km}$ and an area of 25,500 $\mathrm{km}^{2}$ within the MPA, for the detection of acoustically tagged marine fauna, with 82 of the 93 receivers in waters of depths $45 \mathrm{~m}$ or less. All receivers were situated far enough apart to avoid overlap in their detection range, with mean distance to closest receiver $2.15 \mathrm{~km}$, with a range of $0.55-4.57 \mathrm{~km}$. The frequency distribution of inter-receiver distances can be found in Additional file 1: Figure S1. Although range testing has not been undertaken for this array due to financial and logistical constraints of vessel time in the BIOT MPA, other studies conducted around coral atolls in the Indian Ocean using the same or similar equipment have found detection ranges between 300 and $500 \mathrm{~m}(12,38-40)$. Maps of the different reef systems with acoustic coverage with an estimated $500 \mathrm{~m}$ detection range, can be found in Additional file 1: Figure S2-4.

We tagged 102 grey reef and 76 silvertip sharks with acoustic transmitters across nine different locations following the methodology described by Carlisle et al. (6). Of tagged grey reef sharks, 76 were female and 26 were male. Of the tagged silvertip sharks, 45 were female and 31 were male. As in previous studies $(41,42$ ), silvertip sharks (mean total length, $T L=123.56 \mathrm{~cm} \pm 19.14$ ) were on average larger than grey reef sharks (mean $T L=119.15 \mathrm{~cm} \pm 18.07$ ). Detailed information on metadata for each tagged individual can be found in Additional file; Table S1. Tags acoustically transmit a unique ID code with a nominal delay of 60-180 secs for the duration of their battery life ( 10 years), providing a long-term time series of detection data. Receivers were downloaded and serviced annually at the same time each year (March-May), with data last downloaded April 2019.

Only complete years were included in the analysis, with the final data set covering shark detections from 2014-2018. Prior to analysis, data from the seamounts were removed. Seamounts in the BIOT MPA differ ecologically from the rest of the archipelago and recent

Page 3/18 
analyses suggest that they are potentially important drivers of silvertip shark movement (unpublished data). While we acknowledge the ecological importance of seamounts, we only had acoustic equipment on two of these features in the south of the MPA. We felt that in order to robustly investigate segregation of reef sharks in coral reef habitat, seamount data should be excluded.

Movement classification

Using a movement network approach a 'transition' was deemed to have occurred when an individual left one receiver and arrived at another in a new location (24). Alternatively, an animal might leave a receiver, move out of detection range and then return to the same location, a 'self-loop' in network parlance, but here called a 'recursion'. Classification of 'restricted' and 'wider ranging' activity was, therefore, inferred based on the duration of these two different types of movement (hereafter transitions and recursions) before being used as a binary response variable in subsequent models (Fig. 2).

Classification of 'restricted' and 'wider ranging' movements, was conducted using an optimal classification method, where similar data values are placed in the same class by minimising an objective measure of classification error (43). For recursions, detection gaps of less than six minutes (minimum of two detections) were removed from the data as an initial filter to ensure a recursion had taken place, rather than an animal had stayed in the same location but a detection had been missed. Time differences for recursive movements per species were log transformed to normalise the data, and the class intervals function in the 'classint' package in R (44) used to calculate thresholds between 'restricted' and 'wider ranging' movements. The Fisher algorithm was used, which determines thresholds by minimising the sum of absolute intra-class mean variance, as well as maximising inter-class mean variance $(43,45)$. This resulted in a threshold of 91 minutes for grey reef sharks and 64 minutes for silvertip sharks for 'restricted' activity, beyond which it was assumed that the shark had conducted more 'wider ranging' movements.

Transitions were subject to a separate filtering process. Unlike recursions, no initial filter was required for transitions as the detection of an individual on one followed by another receiver is immediately indicative of a movement from one location to another. Temporal gaps in the detection data for any given pair of receivers were informed by both the distance and speciesspecific minimum sustainable swim speeds $(0.69 \mathrm{~m} / \mathrm{s}$ for grey reef sharks and $0.73 \mathrm{~m} / \mathrm{s}$ for silvertip sharks) (46). For example, the predicted transition duration of a direct movement of a shark between two receivers, without deviation, would be the ratio between distance and speed. As such, by first calculating expected time for a transition using swim speeds and distance between receivers, the relative deviation from this expected time (RDET) between any pair of receivers was determined by dividing the expected transition time by the observed transition time. RDET values of $>1$ were movements faster than expected, and values of $<1$ slower/more tortuous than expected.

For transitions, log transformed RDET were constructed for both species, and, as with recursions, an optimal classification method for determining thresholds was used. Movement values of greater than the threshold value of 0.164 for grey reef sharks and 0.128 for silvertip sharks were determined as 'restricted', with values less than the thresholds determined as 'wider ranging'. Animals rarely travel in straight lines and often vary in their tortuousity depending on factors such as resource use, habitat quality, competition and predation (47-49). These thresholds of 0.164 and 0.128 are, therefore, very conservative to allow for a tortuous movement to occur and still be classified as 'restricted' in each species. Finally, recursions and transitions were combined so that every movement was categorised as a binary response (restricted $=0$, wider ranging $=1)($ Fig. 2).

Data analysis

To explore the influence of explanatory variables on 'wider ranging' movements, an information theoretic approach was taken, which accounts for model selection uncertainty $(50,51)$, using a generalised linear mixed model (GLMM). In recent years, information theoretic approaches have become a staple for modelling ecological systems, particularly those where explanatory models describing the system may have similar complexity and fit the data equally well, such as understanding the spatial distribution $(52-54)$, behaviour $(55,56)$, and anthropogenic impact on survival of wildlife populations $(57,58)$. To limit exploratory analyses, and prevent model overfitting, an a priori selection of variables and interactions based on previous research and theory was conducted $(51,59,60)$. Explanatory variables included in the model were 'species', 'sex', 'size', 'season' (wet/dry) and 'diel period' (day/night) (15, 42, 61-63). As size had a non-normal distribution it was log transformed. The BIOT MPA is located near the equator and has a roughly 12-hour day/night cycle. As such, day was designated from 0700 to 1900 and night from 1900 to 0700 following sunrise and sunset times obtained from https://www.timeanddate.com. The MPA experiences distinct Indian Ocean wet and dry seasons with wet season running from October to March, and dry season from April to September (64). Seasonal variability is often greater than monthly variability in tropical ocean systems $(65,66)$, and, therefore we deemed season a more biologically relevant driver of shark movement. All analyses were conducted in R version 3.6.0 (67). 
All variables used in the model were assessed for multicollinearity. Multicollinearity, which occurs when predictors in a multiple regression are highly correlated (68), was assessed by producing a variance inflation factor (VIF) using the 'check_collinearity' function in the 'performance' package in R (69). VIF measures the degree of multicollinearity in a regression model by providing an index of how much the variance of the model variables increases due to collinearity (70). No evidence of collinearity was found, with all variables having a VIF $\leq$ 1.05 , less than the critical threshold of 5.0 (see Additional file 1: Table S2) $(68,71)$. As such, all a priori selected explanatory variables were included in the global model.

A global model was subsequently created using a GLMM (family binomial) in the glmmTMB package (72). To explore putative spatial and temporal segregation between grey reef and silvertip sharks, 'species' was included as interaction term with all explanatory variables and individual ID as random factor. As the likelihood of a movement between locations decays as a function of distance (D. Jacoby unpublished data), receiver location was also included as an independent random factor. Residuals of the global model were checked for heteroscedasticity, autocorrelation and errors were checked for binomial distribution using the functions 'resid', 'fitted', and 'acf' from the 'stats' package in R (67) and found free from autocorrelation and heteroscedasticity of residuals (Additional file 1: Figure S5).

To generate the model set from the global model, the dredge function from the MuMln package was used (73). These models were ranked by Akaike information criterion (AIC) values. If no single parsimonious model resulted from the model set, a group of confidence models, most likely to represent the system, were selected. Only models with delta AIC $<2$ were chosen for the confidence model set $(50,74)$. A model averaging approach was then undertaken on the confidence set of models (60) using the model averaging function in the MuMln package (73). This function calculates model weights based on the confidence set of models (60). Model averaged estimates and confidence intervals $(97.5 \%)$ for each explanatory variable and interactions were calculated (51). The relative importance of each predictor variable (relative to other variables in the confidence set of models) was calculated by summing Akaike weights for all confidence set models containing them (50).

Model averaged estimate values indicate the probability of observing a 'wider ranging' movement as the value for continuous predictor variables increase. Categorical predictor variables were compared to the categorical variable level used as the model baseline. Positive estimates indicate an increased probability of 'wider ranging' and a decreased probability of 'restricted' movements; negative estimates, a decreased probability of 'wider ranging' and increased probability of 'restricted' movements. It is important to note that using this method it is possible that some levels of categorical predictors may display a high relative importance value but show no significant result in the model averaged estimates, as these are dependent on the baseline chosen (75). Therefore, both the relative importance and model averaged estimate results should be considered in combination $(55,60)$. To assess variance in the fixed effects and the entire model, marginal $R^{2}$ and conditional $R^{2}$ values were calculated using r.squaredGLMM in the MuMIn package $(73,76)$.

Model cross-validation

To assess the predictive capabilities of our final model, analysis was conducted on $80 \%$ of the data. Cross-validation of the model averaged estimate values from the confidence set of models was conducted on the remaining $20 \%$ of data as confirmatory analysis to quantify how well the selected model performed (51). The predict function in the glmmTMB package was used to validate the expected outputs of the multi-model inference on the observed values from the reserved $20 \%$ of the data. Area under the receiver operating characteristic curve (AUC) values designate the probability that positive and negative instances are correctly classified (77). As such, AUC was calculated using the pROC package (78), as a thresholdindependent method to check the robustness of the model. An AUC value of greater than 0.7 indicates better than random performance and that the model is a good representation of the system being evaluated (77, $79,80)$.

\section{Results}

There were 768,081 movements (transitional and recursive) identified from 102 grey reef sharks and 76 silvertip sharks between 20142018.

Model selection

Following the dredge of the global model, no single parsimonious model was found. The weight of the best model was 0.17 (Additional file 1 : Table S3). If the weight of the 'best' model is less than 0.9 , model averaging is recommended over model comparison (60). Six models had $\triangle \mathrm{AIC}<2$ and formed the confidence model set for model averaging (Table 1). As part of model averaging, model weights are recalculated (60). The results from model averaging are presented in Table 2. Five variables and three interactions had a relative 
importance greater than 0 and were deemed as important explanatory variables of 'wider ranging' movements (Table 2). Three variables and one interaction had a significant effect on 'wider ranging' movements (Table 2).

Table 1

Confidence set of models resulting from model selection.

\begin{tabular}{|c|c|c|c|c|c|c|c|c|c|}
\hline Model & $\begin{array}{l}\text { diel } \\
\text { stage }\end{array}$ & size & season & sex & species & $\begin{array}{l}\text { diel } \\
\text { stage:species }\end{array}$ & size:species & season:species & sex:species \\
\hline 54 & + & NA & + & NA & + & + & NA & NA & NA \\
\hline 182 & + & NA & + & NA & + & + & NA & + & NA \\
\hline 62 & + & NA & + & + & + & + & NA & NA & NA \\
\hline 318 & + & NA & + & + & + & + & NA & NA & + \\
\hline 190 & + & NA & + & + & + & + & NA & + & NA \\
\hline 56 & + & -0.13 & + & NA & + & + & NA & NA & NA \\
\hline Model & df & logLik & $\mathrm{AlCc}$ & $\triangle \mathrm{AlC}$ & $\omega$ & & & & \\
\hline 54 & 7 & -179034.1632 & 358082.3267 & 0.00 & 0.28 & & & & \\
\hline 182 & 8 & -179033.5974 & 358083.1951 & 0.87 & 0.18 & & & & \\
\hline 62 & 8 & -179033.6551 & 358083.3104 & 0.98 & 0.17 & & & & \\
\hline 318 & 9 & -179032.8144 & 358083.6291 & 1.30 & 0.15 & & & & \\
\hline 190 & 9 & -179033.0848 & 358084.17 & 1.84 & 0.11 & & & & \\
\hline 56 & 8 & -179034.0975 & 358084.1952 & 1.87 & 0.11 & & & & \\
\hline
\end{tabular}


Table 2

Model averaging results following model selection for wider ranging movements.

\begin{tabular}{|c|c|c|c|c|c|c|c|}
\hline & Estimate & Std. Error & $\mathrm{Cl}$ & & $z$ value & $p$ value & $\mathbf{R} \mathbf{I}$ \\
\hline Intercept & -2.02 & 0.636 & -3.448 & -0.956 & 3.465 & 0.001 & NA \\
\hline \multicolumn{8}{|l|}{ diel period } \\
\hline night & 0.133 & 0.011 & 0.110 .155 & & 11.593 & 0.000 & 1.000 \\
\hline \multicolumn{8}{|l|}{ season } \\
\hline wet season & 0.169 & 0.011 & 0.1470 .19 & & 15.304 & 0.000 & 1.000 \\
\hline \multicolumn{8}{|l|}{ species } \\
\hline silvertip shark & 0.805 & 0.148 & 0.5151 .094 & & 5.445 & 0.000 & 1.000 \\
\hline \multicolumn{8}{|l|}{ diel period:species } \\
\hline night:silvertip shark & 0.076 & 0.018 & 0.0390 .112 & & 4.092 & 0.000 & 1.000 \\
\hline \multicolumn{8}{|l|}{ season:species } \\
\hline wet season:silvertip shark & -0.021 & 0.02 & -0.0590 .018 & & 1.065 & 0.287 & 0.292 \\
\hline \multicolumn{8}{|l|}{ sex } \\
\hline male & 0.203 & 0.182 & -0.1550 .56 & & 1.111 & 0.266 & 0.429 \\
\hline \multicolumn{8}{|l|}{ sex:species } \\
\hline male:silvertip shark & -0.37 & 0.285 & -0.9270 .188 & & 1.298 & 0.194 & 0.146 \\
\hline size & -0.133 & 0.367 & -0.8520 .586 & & 0.362 & 0.717 & 0.110 \\
\hline \multicolumn{8}{|c|}{$\begin{array}{l}\text { Estimates with standard error, } 97.5 \% \text { confidence intervals }(\mathrm{Cl}) \text { and associated p values are presented. Significant results are highlighte } \\
\text { in bold. Relative importance (RI) of each model calculated by summing Akaike weights (Table } 1 \text { ) for all set of confidence models } \\
\text { containing them. A value of one indicates a variable is very important and occurred in all confident set of models, a value of } 0 \\
\text { indicating a variable is unimportant and did not occur in any confidence set of models. }\end{array}$} \\
\hline
\end{tabular}

Model averaging

Species, diel period and season were significant predictors of 'wider ranging' movements. Silvertip sharks were overall more likely to undertake 'wider ranging' movements compared to grey reef sharks $(p<0.001$, Table 2$)$ indicating spatial segregation between the species. However, as both species still undertook regular 'wider ranging' and 'restricted' movements, this segregation is not discrete. Wider ranging' movements were more likely to occur at night than during the day $(p<0.001$, Table 2) (Fig. 3a), and during the wet season than the dry season ( $p<0.001$, Table 2) (Fig. 3b). Interaction effects revealed temporal segregation of movements between the species with the difference in 'wider ranging' movements between silvertip sharks and grey reef sharks greater at night than during the day ( $p<0.001$, Table 2) (Fig. 3a). The variance and standard deviation of the random factors were 0.67 and 0.82 for individual ID, and 0.77 and 0.88 for receiver location respectively. Marginal $R^{2}(R 2 m)$ was 0.03 and conditional $R^{2}(R 2 c) 0.36$. Model validation results calculated an AUC value of 0.741 , indicating a good performance of the model.

\section{Discussion}

Understanding the spatial and temporal distribution and movement patterns of reef sharks in the BIOT MPA is important for effective conservation management and MPA enforcement efforts. Current analyses of acoustic telemetry data often neglect the timings and periodicity of detection gaps. In the absence of more accurate movement data for large numbers of animals, which can be prohibitively expensive for satellite telemetry, we have developed a new approach, which utilises gaps in detections from acoustic telemetry to infer presence or absence from regions of interest, such as coral reef systems, at a coarse scale. Prior research on patterns of movements between coral reef-associated elasmobranch species have been limited but primarily focus on differences in space use (15, 81, 82). To date, temporal aspects of segregation are rarely considered $(83,84)$. As seen here, the use of time dependent factors, such as detection gaps, has the potential, albeit at coarse scales, to identify both spatial and temporal differences in movement in sympatric shark species enhancing our understanding of the organisation and reorganisation of reef predator assemblages.

Page 7/18 
Grey reef and silvertip sharks in the BIOT MPA had significant differences in inferred 'wider ranging' activity. Overall, silvertip sharks were more likely to undertake 'wider ranging' movements than grey reef sharks. These results suggest spatial segregation between these species, with grey reef sharks, probabilistically, more likely to inhabit reef-based areas while silvertip sharks were more mobile and conducted more widespread movements (Fig. 3). Our results indicate that although there is spatial segregation between the species, there is overlap between the two in the areas they reside. This supports evidence from isotope data which suggests resource partitioning between these two species in the BIOT MPA, with both species utilising both reef and pelagic areas for foraging, but with grey reef sharks obtaining $78 \%$ of their biomass from reef resources, but silvertip sharks only $60 \%$ (85). In addition, our results are consistent with work from the Great Barrier Reef suggesting grey reef sharks are true reef sharks, and silvertip sharks less reliant on reef-based resources in this region (86). Further, these results extend previous research describing variable patterns of movement and activity in both grey reef sharks and silvertip sharks globally (87-89). Locally, previous research in the BIOT MPA found that silvertip sharks had higher mobility, larger activity spaces, and lower reef residency compared to grey reef sharks, which had small activity spaces and rarely moved more than five to ten kilometres from their tagging location (6). This study has shown that not only can gaps in detections be used to help interpret and support other types of data, but, even at coarse scales, can potentially be used to provide insight into the differences in spatio-temporal movements that underpin reef predator sympatry.

Although 'wider ranging' movements of reef sharks in the BIOT MPA increased at night, this is perhaps biased by silvertip shark propensity to range more during the night, with grey reef sharks showing very little diel change in 'wider ranging' movements (Fig. 3a). Differing patterns from the literature suggest that diel movement patterns may be population dependent, possibly driven by interspecific interactions and/or local environmental conditions $(38,87,88)$. For example, grey reef shark populations in Palau utilise shallower reef platforms for foraging during the night, with deeper, pelagic, waters exploited during the day (88). The same species around Palmyra Atoll in the Central Pacific Ocean, however, are detected on the forereef frequently during the day with far fewer detections at night (87), suggesting they move away from the reefs during these periods. To date only a few studies have been conducted on movement behaviour of silvertip sharks, but work by Espinoza et al. (89) on the Great Barrier Reef found that silvertip sharks undertook deeper dives and were detected less during the day, possibly due to foraging. An alternative explanation for the reduction in detections at night, could be the avoidance of transient apex predators, such as tiger sharks (Galeocerdo cuvier), which are known to feed on reef-associated mesopredators, like silvertip sharks (35, 36, 90). Further research should be conducted in order to investigate regional and population patterns of movement both within and between different reef shark species.

The diel variance in 'wide-ranging' movements found in the study also indicates temporal segregation of movements between the two species, with the difference in spatial segregation of grey reef and silvertip sharks increasing at night (Fig. 3a). The reasons behind the increase in spatial segregation at night are not immediately clear. At several other reef locations grey reef sharks are central place foragers $(86,87,91)$, while silvertip sharks are more dispersive, and less site attached $(86,89)$. As foraging occurs at night, it may be that silvertip sharks move offreef to forage, therefore increasing 'wider ranging' movements at night, while grey reef sharks forage on-reef, which would support the differential patterns of resource use found between these species (85). Or, alternatively, it may be that silvertip sharks occupy a greater spatial range at night during foraging, as has been seen in other reef shark species, such as whitetip reef sharks, Triaenodon obesus (92) and blacktip reef sharks, Carcharhinus melanopterus (87), but grey reef shark spatial range rarely changes. However, currently little is known about the foraging ecology of these two species in this region, and further studies will be needed to investigate the apparent diel differences in 'wider ranging' movements between these two species in the region.

There was also seasonal variation in the 'wider ranging' movements of both species (Fig. 3b). Knowledge of seasonal patterns of elasmobranch movement in the region is important to aid enforcement efforts to prevent illegal or unregulated fishing in the BIOT MPA (93). Like diel period, seasonal patterns of movement are common in multiple elasmobranch species. Such seasonality may be driven by mating in adults, ontogenetic expansion of home range, or foraging opportunities $(63,94,95)$. Additionally, environmental conditions across the BIOT MPA are subject to considerable changes associated with the Indian Ocean monsoon current. In many species however, seasonal changes in movement may not be clear, with movements either unpredictable or subject to individual behavioural variability (95). Indeed, our model results suggest that inter-individual variability also plays an important role in explaining the probability of 'wider ranging' movements. Interindividual variability in movement behaviour is seen across shark species (96-98), and may be driven by differences in age class, sex, morphology, health and even personalities $(99,100)$ but currently is not fully understood $(101)$. Model results also indicated an increase in 'wider ranging' movements during the wet season. However, the reasons for this increase are unclear. As the wet season (October - March) coincides with the peak historic pelagic fishing season in the BIOT MPA (102), this increase in movement may possibly be linked to a seasonal food resource, as previously hypothesised by Curnick et al. (85). Although food may be a primary driver of temporal changes in movement, it may also be driven by factors such as thermoregulation or predator avoidance, or by environmental variables such as sea surface temperature, salinity or current $(89,103)$. Despite recent developments to our understanding of how environmental 
variables effect elasmobranch movement $(103,104)$, they are still relatively poorly understood and investigations should be undertaken to further explore their impact on both spatial and temporal aspects of elasmobranch movement in this region.

Because acoustic telemetry only measures presence, array design and detection ranges can significantly impact results obtained using this technology (6). An inability to detect an animal could be due to the animal leaving the study area, or because it moved out of detection range (5), and consequently might result in some mis-designated movements in this study. Detection ranges for the region vary between 300 and $500 \mathrm{~m}(12,38-40)$, and distances between receivers ranged, between 0.55-4.57 km with mean distance to closest receiver $2.15 \mathrm{~km}$, with minimal overlap between receivers (Additional file 1; Figure S1-4). We acknowledge that this could lead to significant 'blind spots', where a shark could be swimming and not detected rather than engaging in 'wide-ranging' movements. We consider the impact of these, however, to be minimal for the following reasons; classification thresholds of movement were very conservative, giving considerable leeway for an animal to move around a reef area, detections to be missed, and still the movement be classed as 'restricted'; furthermore, neither of these species are able to rest motionless on the bottom, as they are required to ram ventilate (105), increasing the chances of them being detected on the same or additional receivers even when frequenting 'blind spots' within the array.

In addition, animals using the lagoons of these atolls would also not necessarily be detected on the array, and movements across the lagoons could also be mis-designated. However, lagoon use in these species tends to be minimal $(41,106,107)$ and the isotope signatures obtained from these two species indicate they are not using lagoons for foraging (85). As such, in addition to our findings complementing the work of Curnick et al. (85), we believe these potential issues should not have impacted our results significantly. However, we stress that this is an inference method being used in lieu of more accurate measurements for large numbers of free-ranging individuals and may not be suitable for regions with large gaps in receiver detection ranges, particularly when the study species may exhibit bouts of sedentary behaviour.

Although the consistent nature of our results with those obtained from stable isotope work (85) help to validate our methodological approach, further validation of our classifications could be carried out using more accurate positional data. Although there were several silvertip sharks double tagged with both acoustic and PSAT tags, unfortunately the positional data from these satellite tags was not of a high enough resolution to fully confirm our claims. At low latitudes, the error associated with light-level geolocation estimates from PSAT tags can be very high (4). For example the geolocation error from a silvertip shark tagged with a PSAT in the BIOT MPA was estimated at $0.25^{\circ}$ or $27.83 \mathrm{~km}$ at the equator (6). In addition, geolocation algorithms used to reconstruct positions from PSAT data only produce a single position per day, which limits their ability to investigate diel differences in location. Although not feasible in this study, the accuracy of this technique should be validated in future studies with more accurate positional data, such as those derived from Fastloc GPS tags (e.g. Smart Positioning and Temperature transmitting tags).

There are no single 'silver bullet' research techniques for investigating elasmobranch ecology at an appropriate and meaningful spatial and temporal scale; each methodology has its limitations. However, by combining data from multiple approaches the limitations of any individual methodology can be overcome, and a more holistic understanding of elasmobranch ecology can be attained. Here we show that, in the absence of finer scale movement data beyond the boundaries of our acoustic detection ranges, gaps in detections can be used to support and extend conclusions about how variable behavioural strategies can influence interspecific species organisation on coral reef systems.

\section{Conclusion}

In the absence of accurate satellite tracking data, we have developed a novel methodological approach for analysing acoustic telemetry data, using absences in detections to classify 'restricted' and 'wider ranging' activity in two sympatric shark species. Our results highlight coarse diel and seasonal differences in the movements of grey reef and silvertip sharks in the BIOT MPA, potentially providing evidence of spatial and temporal segregation in these species. As apex or mesopredators, shark species play an important role in the ecological function of reef, pelagic and coastal ecosystems $(23,27)$. Knowledge of how sympatric shark species interact with each other is therefore important to further determine their ecological function in coral reef ecosystems, which is currently poorly understood. Analysis of movement to investigate segregation in elasmobranchs has, to date, primarily focused on how spatial aspects of movement vary $(15,81)$. However, temporal aspects of movement are also important for investigating interspecific interactions. Despite potential limitations for the technique for some regions and species, this methodology has the potential for investigating movement ecology of marine species in the absence of more accurate, expensive, technologies, or where receivers only cover a singular habitat. To our knowledge, this is the first analysis of acoustic telemetry data to focus on temporal gap analysis to informing movement ecology and to infer both spatial and temporal segregation between two species. This is critical information for the management and conservation of threatened ecosystems 
such as coral reef systems (81), as well as aiding enforcement efforts of MPAs to mitigate against illegal fishing activity that still threatens many protected reserves today.

\section{Abbreviations}

AIC

Akaike Information Criterion

AUC

Area Under the receiver operating characteristic Curve

BIOT

British Indian Ocean Territory

EEZ

Exclusive Economic Zone

GLMM

Generalised Linear Mixed Model

MPA

Marine Protected Area

PSAT

Pop-up Satellite Archival Tag

RDET

Relative Deviation from Expected Time

\section{Declarations}

\section{Ethics approval and consent to participate}

All procedures were approved by the Stanford University Administrative Panel on Laboratory Animal Care (APLAC) under permit APLAC10765.

\section{Consent for publication}

Not applicable

\section{Availability of data and material}

The datasets and code for the analyses conducted during the current study are available from the corresponding author on reasonable request.

\section{Competing interests}

The authors declare that the research was conducted in the absence of any commercial or financial relationships that could be construed as a potential conflict of interest.

\section{Funding}

Funding for this project was provided by the Bertarelli Foundation and contributed to the Bertarelli Programme in Marine Science. This work was also supported by the Natural Environment Research Council (Grant No. NE/L002485/1) to MJW, as part of the London NERC Doctoral Training Partnership at the Department of Geography, King's College London and the Institute of Zoology, London. 
MJW and DMPJ designed and implemented the research. MJW analysed the data. MJW, DMPJ, EJT and TPD wrote the manuscript. FF, $A B C, T K C$, RJS, DMPJ, DMT, BB and DJC collected data and contributed to revisions of the manuscript.

\section{Acknowledgements}

We thank the BIOT Administration for granting us permission to undertake the research.

\section{Author information}

Not applicable

\section{References}

1. Dulvy NK, Fowler SL, Musick JA, Cavanagh RD, Kyne PM, Harrison LR, et al. Extinction risk and conservation of the world's sharks and rays. elife. 2014;3:e00590.

2. Dulvy NK, Simpfendorfer CA, Davidson LNK, Fordham SV, Bräutigam A, Sant G, et al. Challenges and priorities in shark and ray conservation. Curr Biol. 2017;27(11):R565-R72 doi:10.1016/j.cub.2017.04.038.

3. Carrier JC, Heithaus MR, Simpfendorfer CA. Shark research: emerging technologies and applications for the field and laboratory: CRC Press; 2018.

4. Ferreira LC, Mansfield KL, Thums M, Meekan MG. Satellite tracking technologies and their application to shark movement ecology. In: Carrier JC, Heithaus MR, Simpfendorfer CA, editors. Shark research: emerging technologies and applications for the field and laboratory. Boca Raton, FL: CRC Press; 2018. p. 357-77.

5. Heupel MR, Kessel ST, Matley JK, Simpfendorfer CA. Acoustic telemetry. In: Carrier JC, Heithaus MR, Simpfendorfer CA, editors. Shark research: emerging technologies and applications for the field and laboratory. Boca Raton, FL: CRC Press; 2018. p. 133-56.

6. Carlisle AB, Tickler D, Dale JJ, Ferretti F, Curnick DJ, Chapple TK, et al. Estimating space use of mobile fishes in a large marine protected area with methodological considerations in acoustic array design. Front Mar Sci. 2019;6(256) doi:10.3389/fmars.2019.00256.

7. Sheppard C, Sheppard A, Mogg A, Bayley D, Dempsey A, Roche R, et al. Coral bleaching and mortality in the Chagos Archipelago to 2017. Atoll Res Bull. 2017;613:1-25.

8. Koldewey HJ, Curnick D, Harding S, Harrison LR, Gollock M. Potential benefits to fisheries and biodiversity of the Chagos Archipelago/British Indian Ocean Territory as a no-take marine reserve. Mar Pollut Bull. 2010;60(11):1906-15 doi:10.1016/j.marpolbul.2010.10.002.

9. Papastamatiou YP, Meyer CG, Kosaki RK, Wallsgrove NJ, Popp BN. Movements and foraging of predators associated with mesophotic coral reefs and their potential for linking ecological habitats. Mar Ecol Prog Ser. 2015;521:155-70.

10. Mourier J, Planes S. Direct genetic evidence for reproductive philopatry and associated fine-scale migrations in female blacktip reef sharks (Carcharhinus melanopterus) in French Polynesia. Mol Ecol. 2013;22(1):201-14 doi:10.1111/mec.12103.

11. Rizzari JR, Frisch AJ, Magnenat KA. Diversity, abundance, and distribution of reef sharks on outer-shelf reefs of the Great Barrier Reef, Australia. Mar Biol. 2014;161(12):2847-55 doi:10.1007/s00227-014-2550-3.

12. Speed CW, Meekan MG, Field IC, McMahon CR, Stevens JD, McGregor F, et al. Spatial and temporal movement patterns of a multispecies coastal reef shark aggregation. Mar Ecol Prog Ser. 2011;429:261-75.

13. Karanth KU, Srivathsa A, Vasudev D, Puri M, Parameshwaran R, Kumar NS. Spatio-temporal interactions facilitate large carnivore sympatry across a resource gradient. Proc R Soc B. 2017;284(1848):20161860 doi:doi:10.1098/rspb.2016.1860.

14. Carothers JH, Jaksić FM. Time as a niche difference: the role of interference competition. Oikos. 1984;42(3):403-6 doi:10.2307/3544413.

15. Heupel MR, Munroe SEM, Lédée EJI, Chin A, Simpfendorfer CA. Interspecific interactions, movement patterns and habitat use in a diverse coastal shark assemblage. Mar Biol. 2019;166(6):68 doi:10.1007/s00227-019-3511-7. 
16. Amarasekare P. Competitive coexistence in spatially structured environments: a synthesis. Ecol Lett. 2003;6(12):1109-22 doi:10.1046/j.1461-0248.2003.00530.x.

17. Fisher JT, Anholt B, Bradbury S, Wheatley M, Volpe JP. Spatial segregation of sympatric marten and fishers: the influence of landscapes and species-scapes. Ecography. 2013;36(2):240-8 doi:10.1111/j.1600-0587.2012.07556.x.

18. Mourier J, Lédée E, Guttridge T, Jacoby D. Network analysis and theory in shark ecology-methods and applications. In: J. C. Carrier, M. R. Heithaus, Simpfendorfer CA, editors. Shark research: emerging technologies and applications for the field and laboratory. Boca Raton, FL: CRC Press; 2018. p. 337-56.

19. Wilson ADM, Brownscombe JW, Gutowsky LFG, Cooke SJ, Krause J, Krause S, et al. Integrating network analysis, sensor tags, and observation to understand shark ecology and behavior. Behav Ecol. 2015;26(6):1577-86 doi:10.1093/beheco/arv115.

20. Guttridge TL, Gruber SH, DiBattista JD, Feldheim KA, Croft DP, Krause S, et al. Assortative interactions and leadership in a free-ranging population of juvenile lemon shark Negaprion brevirostris. Mar Ecol Prog Ser. 2011;423:235-45.

21. Jacoby DMP, Papastamatiou YP, Freeman R. Inferring animal social networks and leadership: applications for passive monitoring arrays. J R Soc Interface. 2016;13(124):20160676 doi:doi:10.1098/rsif.2016.0676.

22. Findlay R, Gennari E, Cantor M, Tittensor DP. How solitary are white sharks: social interactions or just spatial proximity? Behav Ecol Sociobiol. 2016;70(10):1735-44 doi:10.1007/s00265-016-2179-y.

23. Williams JJ, Papastamatiou YP, Caselle JE, Bradley D, Jacoby DMP. Mobile marine predators: an understudied source of nutrients to coral reefs in an unfished atoll. Proc R Soc B. 2018;285(1875) doi:10.1098/rspb.2017.2456.

24. Jacoby DMP, Brooks EJ, Croft DP, Sims DW. Developing a deeper understanding of animal movements and spatial dynamics through novel application of network analyses. Methods Ecol Evol. 2012;3(3):574-83 doi:10.1111/j.2041-210X.2012.00187.x.

25. Speed CW, Field IC, Meekan MG, Bradshaw CJA. Complexities of coastal shark movements and their implications for management. Mar Ecol Prog Ser. 2010;408:275-93.

26. Creel S, Christianson D. Relationships between direct predation and risk effects. Trends Ecol Evol. 2008;23(4):194-201 doi:10.1016/j.tree.2007.12.004.

27. Ferretti F, Worm B, Britten GL, Heithaus MR, Lotze HK. Patterns and ecosystem consequences of shark declines in the ocean. Ecol Lett. 2010;13(8):1055-71 doi:10.1111/j.1461-0248.2010.01489.x.

28. Heithaus MR, Frid A, Wirsing AJ, Worm B. Predicting ecological consequences of marine top predator declines. Trends Ecol Evol. 2008;23(4):202-10 doi:10.1016/j.tree.2008.01.003.

29. McCauley DJ, Hoffmann E, Young HS, Micheli F. Night shift: expansion of temporal niche use following reductions in predator density. PLoS ONE. 2012;7(6):e38871 doi:10.1371/journal.pone.0038871.

30. Calabrese JM, Fagan WF. A comparison-shopper's guide to connectivity metrics. Front Ecol Environ. 2004;2(10):529-36 doi:10.1890/1540-9295(2004)002[0529:ACGTCM]2.0.CO;2.

31. Jacoby DMP, Freeman R. Emerging network-based tools in movement ecology. Trends Ecol Evol. 2016;31(4):301-14 doi:10.1016/j.tree.2016.01.011.

32. Carter MID, Bennett KA, Embling CB, Hosegood PJ, Russell DJF. Navigating uncertain waters: a critical review of inferring foraging behaviour from location and dive data in pinnipeds. Mov Ecol. 2016;4(1):25 doi:10.1186/s40462-016-0090-9.

33. Poulakis GR, Stevens PW, Timmers AA, Stafford CJ, Simpfendorfer CA. Movements of juvenile endangered smalltooth sawfish, Pristis pectinata, in an estuarine river system: use of non-main-stem river habitats and lagged responses to freshwater inflow-related changes. Environ Biol Fishes. 2013;96(6):763-78 doi:10.1007/s10641-012-0070-x.

34. Chapman ED, Miller EA, Singer GP, Hearn AR, Thomas MJ, Brostoff WN, et al. Spatiotemporal occurrence of green sturgeon at dredging and placement sites in the San Francisco estuary. Environ Biol Fishes. 2019;102(1):27-40 doi:10.1007/s10641-018-0837-9.

35. Heupel MR, Knip DM, Simpfendorfer CA, Dulvy NK. Sizing up the ecological role of sharks as predators. Mar Ecol Prog Ser. 2014;495:291-8.

36. Roff G, Doropoulos C, Rogers A, Bozec Y-M, Krueck NC, Aurellado E, et al. The ecological role of sharks on coral reefs. Trends Ecol Evol. 2016;31(5):395-407 doi:10.1016/j.tree.2016.02.014.

37. Sheppard CRC, Bowen BW, Chen AC, Craig MT, Eble J, Fitzsimmons N, et al. British Indian Ocean Territory (the Chagos Archipelago): setting, connections and the marine protected area. In: Sheppard CRC, editor. Coral Reefs of the United Kingdom Overseas Territories. Dordrecht: Springer Netherlands; 2013. p. 223-40.

38. Field IC, Meekan MG, Speed CW, White W, Bradshaw CJA. Quantifying movement patterns for shark conservation at remote coral atolls in the Indian Ocean. Coral Reefs. 2011;30(1):61-71 doi:10.1007/s00338-010-0699-x.

Page 12/18 
39. Forget FG, Capello M, Filmalter JD, Govinden R, Soria M, Cowley PD, et al. Behaviour and vulnerability of target and non-target species at drifting fish aggregating devices (FADs) in the tropical tuna purse seine fishery determined by acoustic telemetry. Can J Fish Aquat Sci. 2015;72(9):1398-405 doi:10.1139/cjfas-2014-0458.

40. Govinden R, Jauhary R, Filmalter J, Forget F, Soria M, Adam S, et al. Movement behaviour of skipjack (Katsuwonus pelamis) and yellowfin (Thunnus albacares) tuna at anchored fish aggregating devices (FADs) in the Maldives, investigated by acoustic telemetry. Aquat Living Resour. 2013;26(1):69-77 doi:10.1051/alr/2012022.

41. Barnett A, Abrantes KG, Seymour J, Fitzpatrick R. Residency and spatial use by reef sharks of an isolated seamount and its implications for conservation. PLoS ONE. 2012;7(5):e36574 doi:10.1371/journal.pone.0036574.

42. Espinoza M, Lédée EJI, Simpfendorfer CA, Tobin AJ, Heupel MR. Contrasting movements and connectivity of reef-associated sharks using acoustic telemetry: implications for management. Ecol Appl. 2015;25(8):2101-18 doi:10.1890/14-2293.1.

43. Slocum TA, McMaster RB, Kessler FC, Howard HH. Thematic cartography and geovisualization. 3rd ed. ed. Upper Saddle River, NJ: Pearson Prentice Hall; 2009.

44. Bivand R, Ono H, Dunlap R, Stigler M, Denney B: classInt: choose univariate class intervals. 2019: https://cran.rproject.org/web/packages/classint/index.html.

45. Fisher WD. On grouping for maximum homogeneity. J Am Stat Assoc. 1958;53(284):789-98 doi:10.1080/01621459.1958.10501479.

46. Jacoby DMP, Siriwat P, Freeman R, Carbone C. Is the scaling of swim speed in sharks driven by metabolism? Biol Lett. 2015;11(12):20150781 doi:10.1098/rsbl.2015.0781.

47. Roshier DA, Doerr VAJ, Doerr ED. Animal movement in dynamic landscapes: interaction between behavioural strategies and resource distributions. Oecologia. 2008;156(2):465-77 doi:10.1007/s00442-008-0987-0.

48. Gurarie E, Andrews RD, Laidre KL. A novel method for identifying behavioural changes in animal movement data. Ecol Lett. 2009;12(5):395-408 doi:10.1111/j.1461-0248.2009.01293.x.

49. Fahrig L. Non-optimal animal movement in human-altered landscapes. Funct Ecol. 2007;21(6):1003-15 doi:10.1111/j.13652435.2007.01326.x.

50. Burnham KP, Anderson DR. Model selection and multimodel inference: a practical information-theoretic approach. 2 ed. New York, New York, USA: Springer; 2002.

51. Harrison XA, Donaldson L, Correa-Cano ME, Evans J, Fisher DN, Goodwin CED, et al. A brief introduction to mixed effects modelling and multi-model inference in ecology. PeerJ. 2018;6:e4794 doi:10.7717/peerj.4794.

52. Rhodes JR, McAlpine CA, Zuur AF, Smith GM, leno EN. GLMM applied on the spatial distribution of koalas in a fragmented landscape. Mixed effects models and extensions in ecology with R. New York, NY: Springer New York; 2009. p. 469-92.

53. Greaves RK, Sanderson RA, Rushton SP. Predicting species occurrence using information-theoretic approaches and significance testing: an example of dormouse distribution in Cumbria, UK. Biol Conserv. 2006;130(2):239-50 doi:10.1016/j.biocon.2005.12.017.

54. Diniz-Filho JAF, Rangel TFLVB, Bini LM. Model selection and information theory in geographical ecology. Glob Ecol Biogeogr. 2008;17(4):479-88 doi:10.1111/j.1466-8238.2008.00395.x.

55. Kavanagh AS, Owen K, Williamson MJ, Blomberg SP, Noad MJ, Goldizen AW, et al. Evidence for the functions of surface-active behaviors in humpback whales (Megaptera novaeangliae). Mar Mamm Sci. 2017;33(1):313-34 doi:10.1111/mms.12374.

56. Garamszegi LZ. Information-theoretic approaches to statistical analysis in behavioural ecology: an introduction. Behav Ecol Sociobiol. 2011;65(1):1-11 doi:10.1007/s00265-010-1028-7.

57. Currey RJC, Dawson SM, Slooten E, Schneider K, Lusseau D, Boisseau OJ, et al. Survival rates for a declining population of bottlenose dolphins in Doubtful Sound, New Zealand: an information theoretic approach to assessing the role of human impacts. Aquat Conserv Mar Freshw Ecosyst. 2009;19(6):658-70 doi:10.1002/aqc.1015.

58. Aronson MF, La Sorte FA, Nilon CH, Katti M, Goddard MA, Lepczyk CA, et al. A global analysis of the impacts of urbanization on bird and plant diversity reveals key anthropogenic drivers. Proc R Soc B. 2014;281(1780):20133330.

59. Dochtermann NA, Jenkins SH. Developing multiple hypotheses in behavioral ecology. Behav Ecol Sociobiol. 2011;65(1):37-45 doi:10.1007/s00265-010-1039-4.

60. Grueber CE, Nakagawa S, Laws RJ, Jamieson IG. Multimodel inference in ecology and evolution: challenges and solutions. J Evol Biol. 2011;24(4):699-711 doi:10.1111/j.1420-9101.2010.02210.x.

61. Andrews KS, Williams GD, Farrer D, Tolimieri N, Harvey CJ, Bargmann G, et al. Diel activity patterns of sixgill sharks, Hexanchus griseus: the ups and downs of an apex predator. Anim Behav. 2009;78(2):525-36 doi:10.1016/j.anbehav.2009.05.027. 
62. DiGirolamo AL, Gruber SH, Pomory C, Bennett WA. Diel temperature patterns of juvenile lemon sharks Negaprion brevirostris, in a shallow-water nursery. J Fish Biol. 2012;80(5):1436-48 doi:10.1111/j.1095-8649.2012.03263.x.

63. Dudgeon CL, Lanyon JM, Semmens JM. Seasonality and site fidelity of the zebra shark, Stegostoma fasciatum, in southeast Queensland, Australia. Anim Behav. 2013;85(2):471-81 doi:10.1016/j.anbehav.2012.12.013.

64. Sheppard CRC, Ateweberhan M, Bowen BW, Carr P, Chen CA, Clubbe C, et al. Reefs and islands of the Chagos Archipelago, Indian Ocean: why it is the world's largest no-take marine protected area. Aquat Conserv. 2012;22(2):232-61 doi:10.1002/aqc.1248.

65. Huang B, Kinter III JL. Interannual variability in the tropical Indian Ocean. J Geophys Res Oceans. 2002;107(C11):20-1--6 doi:10.1029/2001jc001278.

66. Servain J, Picaut J, Busalacchi AJ. Interannual and seasonal variability of the tropical Atlantic Ocean depicted by sixteen years of seasurface temperature and wind stress. In: Nihoul JCJ, editor. Coupled Ocean-Atmosphere Models. 40. Leige, Belgium: Elsevier; 1985. p. 211-37.

67. R Core Team: R: a language and environment for statistical computing. R Foundation for Statistical Computing 2019: https://www.Rproject.org/.

68. McGowan BS, Wasko M, Vartabedian BS, Miller RS, Freiherr DD, Abdolrasulnia M. Understanding the factors that influence the adoption and meaningful use of social media by physicians to share medical information. J Med Internet Res. 2012;14(5):e117 doi:10.2196/jmir.2138.

69. Lüdecke D, Makowski D, Waggoner P: performance: assessment of regression models performance. R package version 0.2.0. 2019: https://CRAN.R-project.org/package=performance.

70. O'brien RM. A caution regarding rules of thumb for variance inflation factors. Qual Quant. 2007;41(5):673-90 doi:10.1007/s11135-0069018-6.

71. Welzel C, Deutsch F. Emancipative values and non-violent protest: the importance of 'ecological' effects. Br J Political Sci. 2011;42(2):465-79 doi:10.1017/S0007123411000421.

72. Brooks ME, Kristensen K, van Benthem KJ, Magnusson A, Berg CW, Nielsen A, et al. glmmTMB balances speed and flexibility among packages for zero-inflated generalized linear mixed modeling. R J. 2017;9(2):378-400.

73. Bartoń K: MuMIn: multi-model inference. R package version 0.12.2. 2009: http://r-forge.r-project.org/projects/mumin/.

74. Symonds MRE, Moussalli A. A brief guide to model selection, multimodel inference and model averaging in behavioural ecology using Akaike's information criterion. Behav Ecol Sociobiol. 2011;65(1):13-21 doi:10.1007/s00265-010-1037-6.

75. Tonidandel S, LeBreton JM. Relative importance analysis: a useful supplement to regression analysis. J Bus Psychol. 2011;26(1):1-9 doi:10.1007/s10869-010-9204-3.

76. Nakagawa S, Schielzeth H. A general and simple method for obtaining R2 from generalized linear mixed-effects models. Methods Ecol Evol. 2013;4(2):133-42 doi:10.1111/j.2041-210x.2012.00261.x.

77. Siders ZA, Westgate AJ, Johnston DW, Murison LD, Koopman HN. Seasonal variation in the spatial distribution of basking sharks (Cetorhinus maximus) in the lower Bay of Fundy, Canada. PLoS ONE. 2013;8(12):e82074 doi:10.1371/journal.pone.0082074.

78. Robin X, Turck N, Hainard A, Tiberti N, Lisacek F, Sanchez J-C, et al. pROC: an open-source package for R and S+ to analyze and compare ROC curves. BMC Bioinform. 2011;12(1):77 doi:10.1186/1471-2105-12-77.

79. Phillips SJ, Anderson RP, Schapire RE. Maximum entropy modeling of species geographic distributions. Ecol Modell. 2006;190(3):23159 doi:10.1016/j.ecolmodel.2005.03.026.

80. Illán JG, Gutiérrez D, Wilson RJ. The contributions of topoclimate and land cover to species distributions and abundance: fineresolution tests for a mountain butterfly fauna. Glob Ecol Biogeogr. 2010;19(2):159-73 doi:10.1111/j.1466-8238.2009.00507.x.

81. Heupel MR, Lédée EJI, Simpfendorfer CA. Telemetry reveals spatial separation of co-occurring reef sharks. Mar Ecol Prog Ser. 2018;589:179-92.

82. Papastamatiou YP, Wetherbee BM, Lowe CG, Crow GL. Distribution and diet of four species of carcharhinid shark in the Hawaiian Islands: evidence for resource partitioning and competitive exclusion. Mar Ecol Prog Ser. 2006;320:239-51.

83. Bracis C, Bildstein KL, Mueller T. Revisitation analysis uncovers spatio-temporal patterns in animal movement data. Ecography. 2018;41(11):1801-11 doi:10.1111/ecog.03618.

84. McClintock BT, Johnson DS, Hooten MB, Ver Hoef JM, Morales JM. When to be discrete: the importance of time formulation in understanding animal movement. Mov Ecol. 2014;2(1):21 doi:10.1186/s40462-014-0021-6.

85. Curnick DJ, Carlisle AB, Gollock MJ, Schallert RJ, Hussey NE. Evidence for dynamic resource partitioning between two sympatric reef shark species within the British Indian Ocean Territory. J Fish Biol. 2019;94(4):680-5 doi:10.1111/jfb.13938.

Page 14/18 
86. Frisch AJ, Ireland M, Rizzari JR, Lönnstedt OM, Magnenat KA, Mirbach CE, et al. Reassessing the trophic role of reef sharks as apex predators on coral reefs. Coral Reefs. 2016;35(2):459-72 doi:10.1007/s00338-016-1415-2.

87. Papastamatiou YP, Watanabe YY, Demšar U, Leos-Barajas V, Bradley D, Langrock R, et al. Activity seascapes highlight central place foraging strategies in marine predators that never stop swimming. Mov Ecol. 2018;6(1):9 doi:10.1186/s40462-018-0127-3.

88. Vianna GMS, Meekan MG, Meeuwig JJ, Speed CW. Environmental Influences on patterns of vertical movement and site fidelity of grey reef sharks (Carcharhinus amblyrhynchos) at aggregation sites. PLoS ONE. 2013;8(4):e60331 doi:10.1371/journal.pone.0060331.

89. Espinoza M, Heupel MR, Tobin AJ, Simpfendorfer CA. Movement patterns of silvertip sharks (Carcharhinus albimarginatus) on coral reefs. Coral Reefs. 2015;34(3):807-21 doi:10.1007/s00338-015-1312-0.

90. Roemer RP, Gallagher AJ, Hammerschlag N. Shallow water tidal flat use and associated specialized foraging behavior of the great hammerhead shark (Sphyrna mokarran). Mar Freshw Behav Physiol. 2016;49(4):235-49 doi:10.1080/10236244.2016.1168089.

91. Papastamatiou YP, Bodey TW, Friedlander AM, Lowe CG, Bradley D, Weng K, et al. Spatial separation without territoriality in shark communities. Oikos. 2018;127(6):767-79 doi:10.1111/oik.04289.

92. Fitzpatrick R, Abrantes KG, Seymour J, Barnett A. Variation in depth of whitetip reef sharks: does provisioning ecotourism change their behaviour? Coral Reefs. 2011;30(3):569-77 doi:10.1007/s00338-011-0769-8.

93. Tickler DM, Carlisle AB, Chapple TK, Curnick DJ, Dale JJ, Schallert RJ, et al. Potential detection of illegal fishing by passive acoustic telemetry. Anim Biotelem. 2019;7(1):1 doi:10.1186/s40317-019-0163-9.

94. Heupel MR, Simpfendorfer CA, Hueter RE. Estimation of shark home ranges using passive monitoring techniques. Environ Biol Fishes. 2004;71(2):135-42 doi:10.1023/B:EBFI.0000045710.18997.f7.

95. Papastamatiou Y, Lowe C. An analytical and hypothesis-driven approach to elasmobranch movement studies. J Fish Biol. 2012;80(5):1342-60.

96. Matich P, Heithaus MR. Individual variation in ontogenetic niche shifts in habitat use and movement patterns of a large estuarine predator (Carcharhinus leucas). Oecologia. 2015;178(2):347-59 doi:10.1007/s00442-015-3253-2.

97. Andrzejaczek S, Gleiss AC, Jordan LKB, Pattiaratchi CB, Howey LA, Brooks EJ, et al. Temperature and the vertical movements of oceanic whitetip sharks, Carcharhinus longimanus. Sci Rep. 2018;8(1):8351 doi:10.1038/s41598-018-26485-3.

98. Meyer CG, Clark TB, Papastamatiou YP, Whitney NM, Holland KN. Long-term movement patterns of tiger sharks Galeocerdo cuvier in Hawaii. Mar Ecol Prog Ser. 2009;381:223-35.

99. Bolnick DI, Amarasekare P, Araújo MS, Bürger R, Levine JM, Novak M, et al. Why intraspecific trait variation matters in community ecology. Trends Ecol Evol. 2011;26(4):183-92 doi:10.1016/j.tree.2011.01.009.

100. Harrison PM, Gutowsky LFG, Martins EG, Patterson DA, Cooke SJ, Power M. Personality-dependent spatial ecology occurs independently from dispersal in wild burbot (Lota lota). Behav Ecol. 2014;26(2):483-92 doi:10.1093/beheco/aru216.

101. Papastamatiou YP, Friedlander AM, Caselle JE, Lowe CG. Long-term movement patterns and trophic ecology of blacktip reef sharks (Carcharhinus melanopterus) at Palmyra Atoll. J Exp Mar Bio Ecol. 2010;386(1):94-102 doi:10.1016/j.jembe.2010.02.009.

102. Mees C, Wilson O, Gater R, Roe J. British Indian Ocean Territory (Chagos Archipelago) - fisheries conservation and management zone. The 2008/09 Inshore Fishery and 2008/09 Recreational Fishery. 2009.

103. Schlaff AM, Heupel MR, Simpfendorfer CA. Influence of environmental factors on shark and ray movement, behaviour and habitat use: a review. Rev Fish Biol Fish. 2014;24(4):1089-103 doi:10.1007/s11160-014-9364-8.

104. Williamson MJ, Tebbs EJ, Dawson TP, Jacoby DMP. Satellite remote sensing in shark and ray ecology, conservation and management. Front Mar Sci. 2019;6(135) doi:10.3389/fmars.2019.00135.

105. Skomal G, Lobel PS, Marshall G. The use of animal-borne imaging to assess post-release behavior as it relates to capture stress in grey reef sharks, Carcharhinus amblyrhynchos. Mar Technol Soc J. 2007;41(4):44-8 doi:10.4031/002533207787441999.

106. Dale JJ, Stankus AM, Burns MS, Meyer CG. The shark assemblage at French Frigate Shoals Atoll, Hawai'i: species composition, abundance and habitat use. PLoS ONE. 2011;6(2):e16962 doi:10.1371/journal.pone.0016962.

107. Economakis AE, Lobel PS. Aggregation behavior of the grey reef shark, Carcharhinus amblyrhynchos, at Johnston Atoll, Central Pacific Ocean. Environ Biol Fishes. 1998;51(2):129-39 doi:10.1023/a:1007416813214.

\section{Figures}




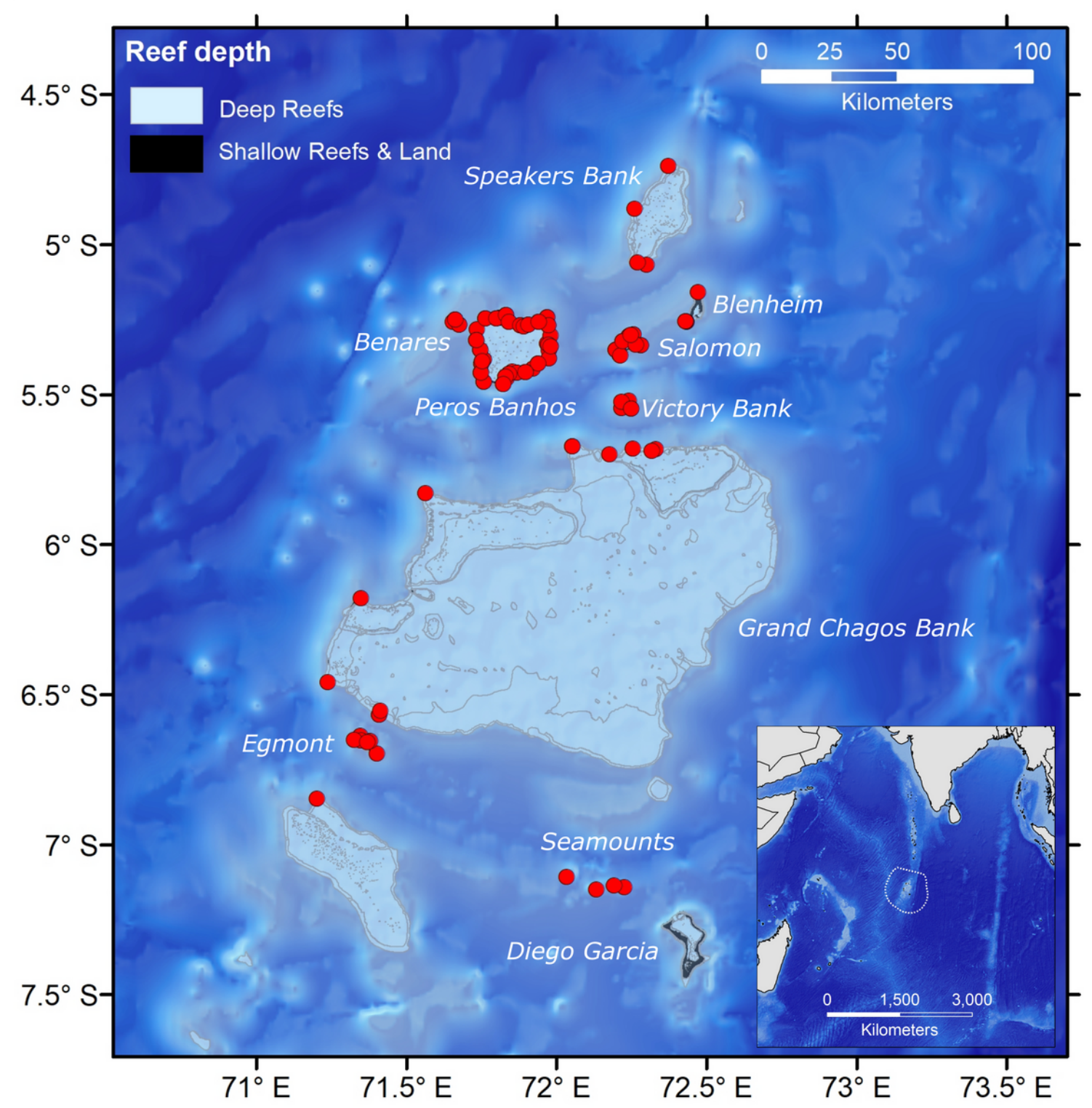

\section{Figure 1}

Acoustic array in the BIOT MPA with the locations of 93 acoustic receivers shown in red, adapted from Carlisle et al. (6). Insert shows the location of the BIOT MPA in the Indian Ocean, with the Exclusive Economic Zone (EEZ) and MPA boundary indicated by the dotted line. Gray lines show the contours of major submerged geographic features. Shallow reefs are $<20 \mathrm{~m}$ in depth, with deep reefs between 20 and $100 \mathrm{~m}$ in depth. 


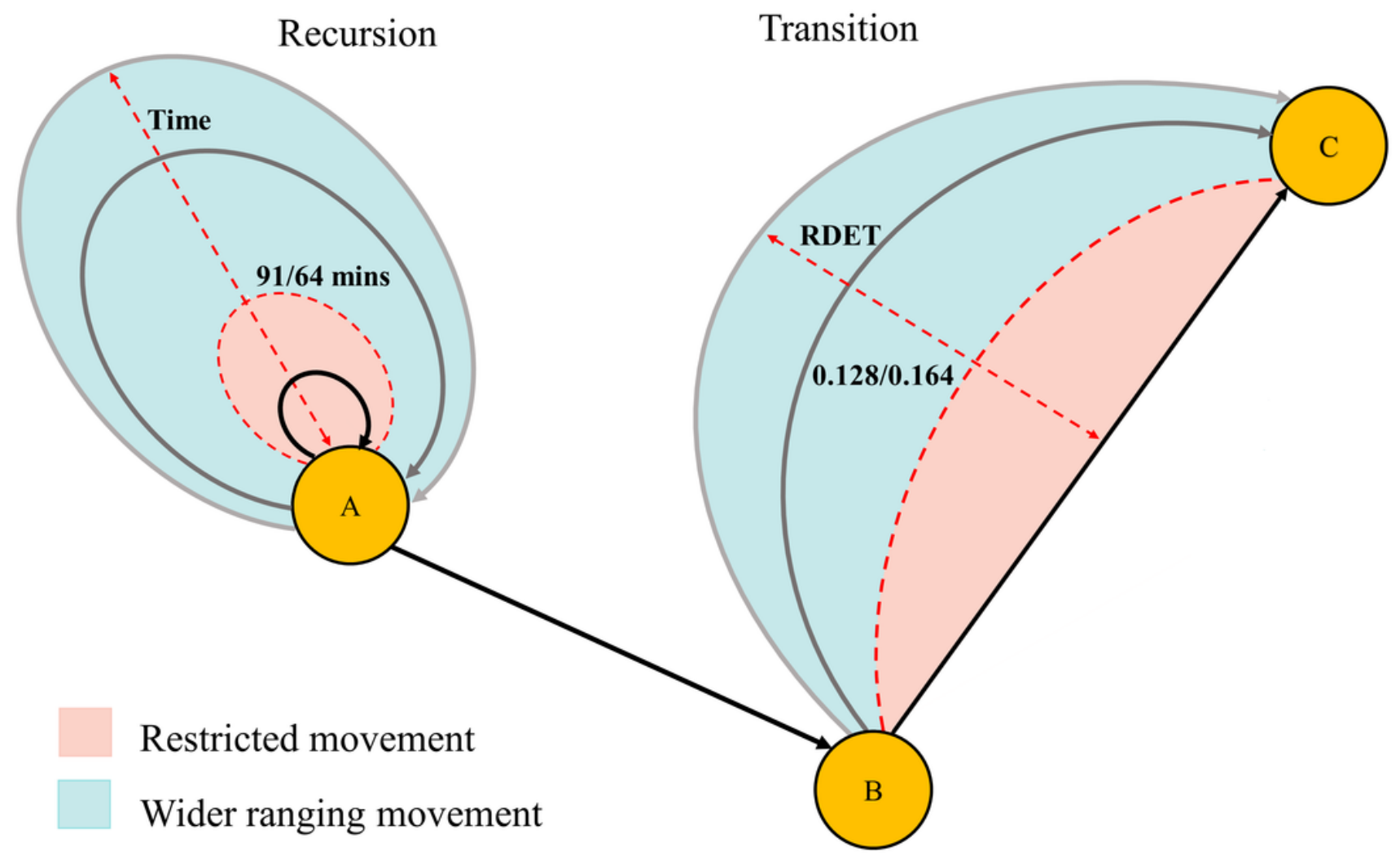

Figure 2

Schematic describing designation of 'restricted' and 'wider ranging' movements. Black and grey arrows indicate a movement either to and from the same point (recursion), or between two points (transition). Time between detections for recursions, and relative deviation from expected time (RDET) for transitions, are represented by length, curvature and colour of the arrow. As time and RDET increase, length and curvature increase, and colour gets lighter indicating less directed movement. Red dashed line indicates our cut-off detection gap (91 minutes for grey reef sharks and 64 minutes) for silvertip sharks for recursions and RDET ( 0.128 for grey reef sharks and 0.164 for silvertip sharks) for transitions. 
a

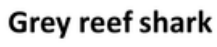

b

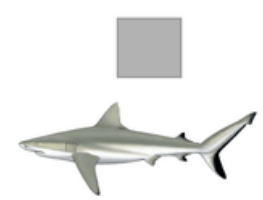

Silvertip shark
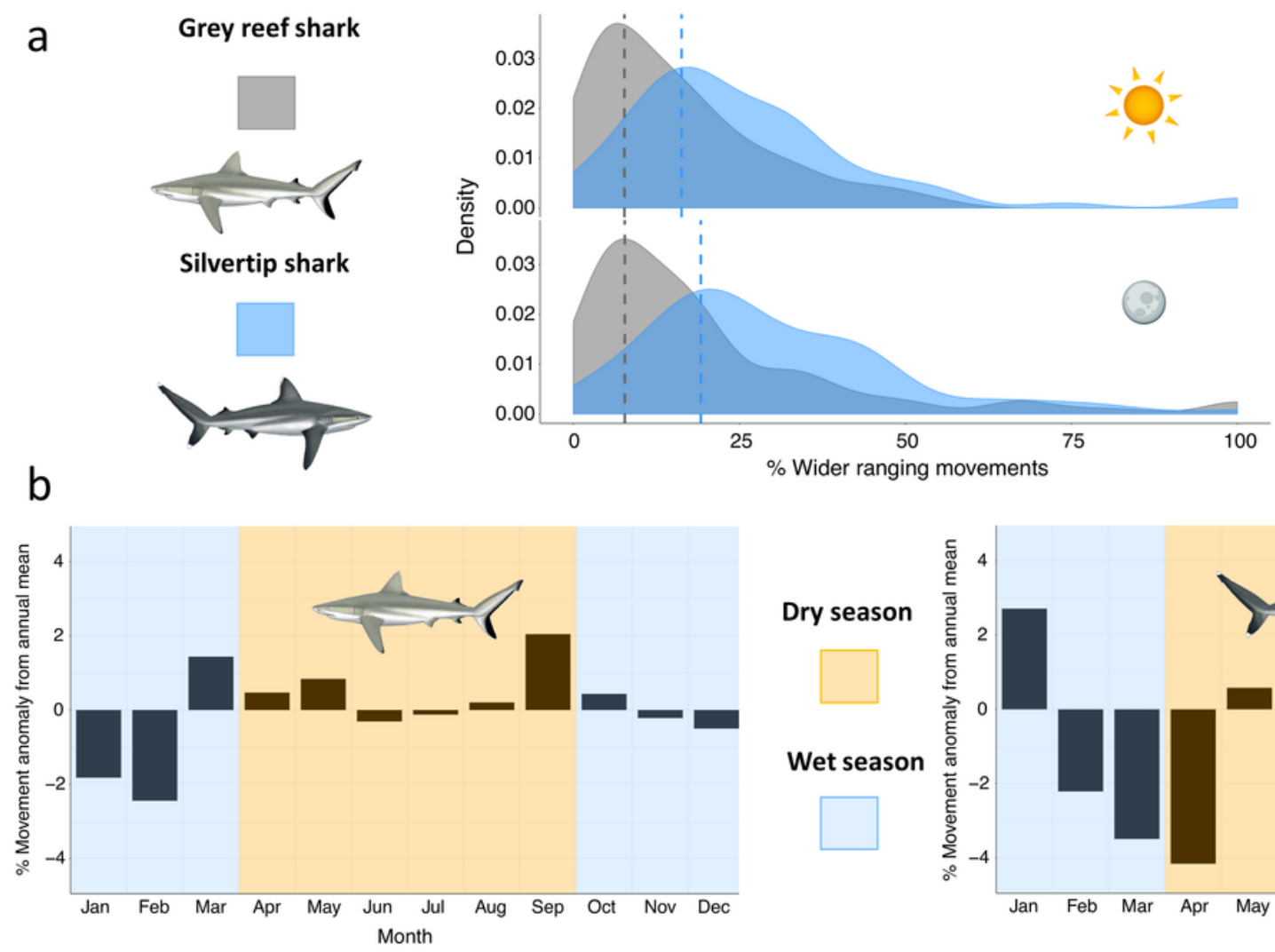

Figure 3

a) Frequency density plots of grey reef shark (grey) and silvertip shark (blue) diel variance in percentage 'restricted' and 'wider ranging' movements, with the sun indicating day-time movements and moon indicating night-time movements. Mean percentage movements for each species are indicated by dashed lines. b) For a more detailed visualisation of seasonality, bar plots of monthly movement anomalies (\%) from the annual mean of 'wider ranging' movements in grey reef (left) and silvertip (right) sharks. Wet (blue) and dry (orange) seasons are highlighted.

\section{Supplementary Files}

This is a list of supplementary files associated with this preprint. Click to download.

- Additionalfile1sub2.docx 